\title{
Tumor-derived exosomes in colorectal cancer progression and their clinical applications
}

\author{
Jianbiao Zhou ${ }^{1,2, *}$, Xiao-Lan Li, ${ }^{3, *}$ Zhi-Rong Chen ${ }^{3}$ and Wee-Joo Chng ${ }^{1,2,4}$ \\ ${ }^{1}$ Cancer Science Institute of Singapore, National University of Singapore, Centre for Translational Medicine, Singapore \\ 117599, Republic of Singapore \\ ${ }^{2}$ Department of Medicine, Yong Loo Lin School of Medicine, National University of Singapore, Singapore 117597, Republic \\ of Singapore \\ ${ }^{3}$ Department of Gastroenterology, Suzhou Municipal Hospital (Eastern), Suzhou Hospital Affiliated to Nanjing Medical \\ University, Suzhou, 215001, China \\ ${ }^{4}$ Department of Hematology-Oncology, National University Cancer Institute of Singapore (NCIS), The National University \\ Health System (NUHS), Singapore 119228, Republic of Singapore \\ *These authors contributed equally to this work and share co-first authors
}

Correspondence to: Wee-Joo Chng, email: mdccwj@nus.edu.sg

Zhi-Rong Chen, email: chen_zr@yahoo.com

Keywords: exosomes, colorectal cancer (CRC), biomarker, cancer therapy, microRNA (miRNA)

Received: April 20, 2017

Accepted: July 30, 2017

Published: August 10, 2017

Copyright: Zhou et al. This is an open-access article distributed under the terms of the Creative Commons Attribution License 3.0 (CC BY 3.0), which permits unrestricted use, distribution, and reproduction in any medium, provided the original author and source are credited.

\section{ABSTRACT}

Colorectal cancer (CRC) ranks as the third leading cause of cancer mortality in both of men and women worldwide due to its metastatic properties and resistance to current treatment. Recent studies have shown that tumor-derived exosomes play emerging roles in the development of cancer. Exosomes are nano-sized extracellular vesicles (EVs) that contain lipids, proteins, DNAs, and RNA species (mRNA, miRNA, long non-coding RNA). These exosomal cargos can be transferred locally and systemically, after taken by recipient cells, so exosomes represent a new form of intercellular communication. There is increasing evidence demonstrating that exosomes control a wide range of pathways bolstering tumor development, metastasis and drug resistance. This review provides an in-depth and timely summary of the role of exosomes in CRC. We first describe the common features and biogenesis of exosomes. We then highlight important findings that support the emerging roles of exosomes in CRC cell growth, invasion and metastasis, as well as resistance to treatment. Finally, we discuss the clinical application of exosomes as diagnostic biomarkers, in vivo drug delivery system and the potential of novel exosome-based immunotherapy for CRC.

\section{INTRODUCTION}

EVs (extracellular vesicles), derived from various cells transfer information efficiently to recipient cells locally or systemically, thus play an important role in numerous biological activities [1]. EVs are divided into three subsets: exosomes, microvesicles, and apoptotic bodies depending on their size [2], and exosomes, in particular, are of great interests among the cancer research community. Exosomal genetic materials that are composed of proteins, messenger RNAs, microRNAs (miRNAs), long non-coding RNAs (lncRNAs), DNAs, lipids and other small molecules, can change the biological behaviors of target cells significantly after being taken in. As such, exosomes represent a distinct type of cellto-cell communication. There is increasing evidence demonstrating the important role of exosomes in tumor development and drug resistance [3]. Colorectal cancer $(\mathrm{CRC})$ is a disastrous disease with high prevalence and low 5-year survival, especially in Stage IV metastatic CRC [4], thereby the urgent need to explore more sensitive diagnostic methods and more efficient treatment. With 
the close association between exosomes and cancer, more researchers are focusing on the specific function of exosomes in colorectal cancer. In this review, we summarize the current knowledge on exosomes in CRC, supporting a key role of exosomes in CRC pathogenesis, biomarkers and therapeutic applications.

\section{Exosomes and their biological functions}

Exosomes of 30-100 nm in diameter, one of the EVs subsets, were first reported as a pattern of cell membrane rollover in sheep reticulocyte maturation $[5,6]$. Since then, a significant volume of research have uncovered the novel functions of exosomes and provided insight into their structures, thus redefining the exosomes field $[7,8]$. Exosomes can be identified in almost all human body fluids, such as blood, urine, saliva, and pathological ascites [9-12]. About 2,000 trillion exosomes have been detected in normal human blood and about 4,000 trillion in blood of cancer patients. In general, cancer cells would generate more exosomes than their normal counterparts [13]. Exosomes are generated in a unique manner from multi-vesicular endosomes (MVEs), also known as multivesicular bodies (MVBs), which are components of the endocytic pathway. The sizes of MVBs range from 250 to $1000 \mathrm{~nm}$ in diameter. The formation of MVEs start from a portion of the limiting membrane of an endosome, invaginating and budding into its own lumen. There are intraluminal vesicles (ILVs) with size of 30 to $100 \mathrm{nM}$ in diameter. If MVBs fuse with lysosomes, its initiates the degradation of ILVs and their contents by lysosomal hydrolases. If MVBs fuse with plasma membrane, ILVs are released into the extracellular space and these released ILVs are defined as exosomes. ESCRT (endosomal sorting complexes required for transport) complexes, sphingolipid ceramide and Rab GTPase (guanosine triphosphate) family (such as Rab11 and Rab27) are involved in the biosynthetic process as key regulatory factors [14-16]. So, some of markers associated with ESCRT are conserved in exosomes secreted by different types of cells, such as Alix, CD63, CD81, TSG101. However, these makers are not exclusive to exosomes, because they also appear in the vesicles derived from membrane shedding.

Emerging evidence indicate that exosomes provide a means for cell-to-cell communication by transporting their cargo and delivering it to target cells locally or remotely. Metaphorically, exosomes are the ships or boats that transfer the cargos, which include DNAs, mRNAs, miRNAs, IncRNAs, proteins, lipids and other metabolites that have biological activities. Notably, the lipid bilayer membrane of exosomes effectively provide their cargos from degradation by separating from the extracellular environment.

The biological behaviors of exosomes are heterogeneous, which could be due to their diverse secretory cell types with different cell status, for instance, endothelial cells, epithelial cells, fibroblasts, neurons, immune cells, and mesenchymal stem cells [13, 17-19]. Through the circulation, exosomes act on target cells, fusing with plasma membrane and releasing contents to exert specific functions. Or, these cargoes can be locally transferred into neighbor cells within the same environment. Great efforts have been made to investigate the distinct mechanisms of exosomes participating in tumorigenesis and progression via various signaling pathways. It has been proven that exosomal contents modify tumor microenvironment, facilitate EMT (epithelial-to-mesenchymal transition) and cytoskeleton reorganization, promote tumor angiogenesis, and influence tumor immunity, resulting in CRC formation, invasion and metastasis, and therefore have important clinical relevance (Figure 1).

\section{Exosomes in the transformation of CRC}

Sporadic CRC is characterized by a multistep transformation of normal colonic mucosa to adenocarcinoma in individuals without genetic predisposition or family history of CRC. After exposure to cancer cell-derived exosomes, epithelial cells with non-malignant phenotype received exosomal cargos, such as oncogenic mRNA or miRNA, and pro-angiogenic proteins, resulting in an altered biological property for tumor initiation [20, 21]. This pioneering work in breast cancer, and glioblastoma indicate that some tumor-derived exosomes are capable of enabling the transformation of normal cells into malignant states. Similarly, it has been shown that exosomes secreted from human CRC cells transfer mRNAs, miRNAs and natural antisense RNAs (asRNAs) into liver cancer and lung cancer cells [1]. The V-Ki-ras2 Kirsten rat sarcoma viral oncogene homolog (KRAS) is a prominent oncogene that encodes a small GTP-binding protein called KRAS. KRAS mutations, mainly in codon 12 or 13 , occur in 35 to $45 \%$ of patients with $\mathrm{CRC}$, and are frequently associated with lung and brain metastasis [22]. Two independent studies have found compelling evidence that mutant KRAS gene influence the compositions and functions of exosomes produced by CRC cells [23, 24]. Proteomic analysis of exosomes secreted by isogenic KRAS wild-type or mutant (G13D) CRC cell line revealed that the composition of the exosomes differ dramatically [24]. Many tumor-promoting proteins, including KRAS, EGFR, SRC family kinases, and integrins are specifically enriched in exosomes from mutant KRAS cells. Importantly, when exosomes released by mutant KRAS cells transfer mutant KRAS protein into these KRAS wide type non-transformed cells, their growth in three-dimensional culture is promoted [24]. The second study examined the global small RNA profiles from exosomes isolated from isogenic CRC cell lines which only differ in their KRAS status [23]. A mutant KRAS-specific pattern of secreted miRNAs 
was observed, indicating KRAS-dependent biogenesis or sorting of exosomal miRNAs. Specifically, miR-10b was selectively increased in KRAS wild-type exosomes, while miR-100 was particularly heightened in mutant exosomes. Notably, miR-100 released by mutant KRAS CRC cells could further amplify miR-100 function in recipient wild-type cells as evidenced by the decreased expression of some target genes of miR-100 [23]. Collectively, these findings are important because they provide novel insight of the contributions of mutant KRAS exosomes to CRC. Therefore, targeting exosome either by inhibiting its production or by blocking its transfer should be exploited in the development of novel treatments for patients with KRAS mutation who are at higher risk of developing metastatic malignancies. A previous study has attempted to detect the mRNA expression with exosomerelated markers in healthy subjects, colorectal adenoma and carcinoma patients [25]. At the in situ protein level, ALIX (ALG 2-interacting protein $X$ ) expression is significantly reduced in adenoma and carcinoma patients compared with healthy persons. ALIX-positive particles including MVB-like structures were found in carcinoma and the surrounding microenvironment of tumor nest. It is therefore suggested that the gradual transition of ALIX, which takes part in multi-vesicular body (MVB) and exosome formation, facilitates the colorectal adenomacarcinoma progression.

It is now established that exosomes are crucial components of the tumor microenvironment. Cancer cell-derived exosomes are able to stimulate fibroblast differentiation into tumour-promoting stromal myofibroblasts through a TGF $\beta 1$-dependent pathway, accelerating angiogenesis and tumor growth [26]. The host microenvironment in which the CRC cells reside is hypoxic, due to increased oxygen consumption as a result of hyperplasia and decreased oxygen delivery. This hypoxic niche protects CRC cells from chemotherapy and attack from immune cells. Under hypoxic conditions, Wnt4 is particularly enriched in exosomes secreted by $\mathrm{CRC}$ cells and increases $\beta$-catenin nuclear translocation in endothelial cells depending on the transcription factor HIF $1 \alpha$. The hyper-activation of $\mathrm{Wnt} / \beta$-catenin signaling by $\mathrm{CRC}$ cell-derived exosomes enhances the proliferation and migration of endothelial cells, promoting tumor growth and angiogenesis in vivo, in animal study [27].

In this regard, CRC cells produce several types of exosomes, which promote the growth and transformation of $\mathrm{CRC}$ by influencing $\mathrm{CRC}$ cells or the reprograming of microenvironment to support $\mathrm{CRC}$ cell proliferation.

\section{Regulation of CRC invasion and metastasis by exosomes}

The 5-year survival rate of CRC patients with distant metastases is extremely poor, less than $10 \%$. Furthermore, approximate $25 \%$ of newly diagnosed CRC patients have distant metastases at presentation [28, 29]. In addition, one in four patients who have localized CRC would develop distant metastases within two years after diagnosis. Therefore, metastasis is an important challenge and the leading cause of death in CRC.

CRC has a characteristic metastatic pattern in which distant metastases appear mainly in the liver and less commonly in the lung, bones and brain [30, 31]. The phenomenon that some types of cancer cells preferentially home and colonize to specific organs is defined as organ tropism. Different type of metastatic cancer cells vary remarkably in organ tropism [32]. For example, pancreatic ductal adenocarcinoma (PDAC) is highly metastatic to liver [33]. Although the pattern of organspecific metastasis is clear, the molecular programs that contribute to this tropism has not been well understood. Recent studies on tumor exosomes shed some light on this longstanding mystery of organotropism for cancer metastatic [34, 35]. Recent reports from the Lyden's laboratory showed that exosomes isolated from lung, liver- and brain-tropic tumor cells fuse preferentially with resident cells respectively at their predicted metastatic sites [34]. Proteomic analysis of these exosome populations uncovered that unique intergrin expression patterns are the determining factors for this organotropism. Specifically, lung-tropic exosomes express intergrins $\mathrm{a}_{6} \beta_{4}$ and $\mathrm{a}_{6} \beta_{1}$, while liver-tropic exosomes express intergrins $\alpha_{v} \beta_{5}$. Taken together, the main function of exosomes in promoting metastasis is to prepare pre-metastatic niche in specific distant organs through the transfer of intergrins or macrophage migration inhibitory factor (MIF) into receipt cells $[34,35]$.

In addition to its important roles in the transformation and growth of CRC cells, stromal or cancer cell-derived exosomes have been proven to induce cancer invasion and metastasis. Data from in vitro and in vivo studies have shown that malignant cells enhance migration behavior and metastatic property of benign cells through cell-to-cell communication by virtue of transferred exosomes to promote tumor progression [36]. When exposed to primary or metastatic CRC-derived exosomes, MSCs (mesenchymal stromal cells) derived from CRC masses not only formed umbilicated spheroids generally observed in the core of growing tumor, but also appeared to undergo functional change with higher proliferation, migration, and invasion [37].

Three recent studies revealed a list of specially expressed miRNAs transferred by exosomes that are involved in proliferation and migration of CRC cells (summarized in Table 1). miR-210 has been known to contribute to EMT, anoikis resistance and metastatic potential in cancers. The expression of miRNA-210 was markedly upregulated in exosomes as compared with its intracellular level in HCT8 cells, indicating its role in maintaining the growth-permissive microenvironment for primary cancer cells and guiding the new location for 
Table 1: Summary of major exosomal miRNAs and their functional roles in CRC

\begin{tabular}{|c|c|c|}
\hline References & Exosomal miRNAs & Major Conclusions \\
\hline [38] & $\operatorname{miR}-210$ & Contributing to EMT, anoikis resistance and metastatic potential \\
\hline [83] & miR-220C, miR-141 & Up-regulating EMT, promoting invasion \\
\hline [42] & miR-375 & Inducing CRC cell apoptosis through blocking Bcl-2 \\
\hline [41] & miR-200c, miR-141, miR-429 & $\begin{array}{l}\text { Decreasing expressions of ZEB } 2 \text { and SNAI, reprogramming the } \\
\text { stroma in the metastatic process }\end{array}$ \\
\hline [61] & $\begin{array}{l}\text { let-7a, miR-1229, miR-1246, miR-150, } \\
\text { miR-21, miR-223, and miR-23a }\end{array}$ & $\begin{array}{l}\text { The serum exosomal level of these } 7 \text { miRNAs are significantly } \\
\text { higher in CRC patients than healthy controls. }\end{array}$ \\
\hline [62] & miRNA-19a & A prognostic biomarker for recurrence in CRC \\
\hline$[63]$ & $\operatorname{miR}-379$ & Inhibiting CRC cells proliferation and migration \\
\hline [64] & miR-193a & patients. \\
\hline [23] & $\operatorname{miR}-100$ & $\begin{array}{l}\text { miR-100 is selectively enriched in exosomes derived from mutant } \\
\mathrm{K}-\mathrm{R} \text { as CRC cells and transferred into wild type CRC cells. }\end{array}$ \\
\hline
\end{tabular}

metastatic cells [38]. The process of EMT refers to the phenomenon in which adhesive, non-mobile epithelial-like cells transform into mesenchymal-like cells, gaining the ability to migrate to distant anatomical sites [39]. Studies in the last decade have documented the essential roles of EMT in the formation of cancer metastasis. One key step in the event of EMT is the loss of E-cadherin and the transcription factors (TFs) which repress E-cadherin, known as EMTinducing TFs, which includes SNAI, ZEB1, ZEB2, E47 and KLF8. Recent research suggests the involvement of exosomes in the induction of EMT, attributing to the metastatic progression of CRC [40]. Exosomal miR-200c, miR-141 and miR-429 from naïve CRC CCL227 cells decreased expressions of ZEB2 and SNAI with the role of direct transcriptional repressors in CRC metastasis. In addition, these exosomal miRNAs decelerated CCIDs (circular chemorepellent-induced defects) formation in blood endothelial cell (BEC)-barrier as well as LEC (lymphatic endothelial cell)-barrier which are the gates of tumor migration via blood vessels and lymphatics [41].

In contrast to the function of the above-mentioned miRNAs as oncogenes, miRNA-375 has been identified as a tumor suppressor gene in CRC. Exosomes isolated from liver metastasis of CRC carrying miR-375 affect CRC cell apoptosis through the Bcl-2 pathway [42]. Bcl-2 was down-regulated in HCT116 cells transfected with the miR-375 mimic, promoting apoptosis. On the contrary, Bcl-2 was up-regulated after HCT116 cells were treated with miR-375 inhibitor, increasing cell proliferation. The liver metastatic CRC cell line (HT-29)derived exosomes increased CXCR4 expression in the metastatic microenvironment further to promote cancer metastasis [43]. A 3D (three-dimensional) model of CRC cells was established to study the mechanisms by which CRC-triggered LEC (lymphatic endothelial cell) and BEC (blood endothelial cell) barriers are breached.

In addition to miRNAs, protein components in the exosomes also have been systematically investigated for their role in the pathogenesis of CRC metastasis Proteome profiling was conducted to compare the protein cargo of exosomes released from two isogenic human colorectal cancer cell lines: one primary cell line and its metastatic variant [44]. This study revealed that metastatic CRC cell exosomes selectively enrich some key metastatic factors and signal transduction molecules compared with primary CRC cell exosomes. Importantly, MET signaling complex, TNIK-RAP2A complex are uniquely expressed in metastatic CRC cell exosomes [44].

Taken together, these observations reveal that exosomes not only determine the site-specific metastasis, but also mediate intercellular communication to stimulate the process of EMT, migration and invasion of CRC cells.

\section{Exosomes induce chemotherapy resistance in CRC}

Currently, chemotherapy remains an important remedy for advanced CRC [45] . However, a large number of patients show various degrees of drug resistance that directly resulted in poor prognosis [46]. The molecular pathways associated with drug resistance have been extensively studied over the last few decades, including overexpression of ATP-binding cassette (ABC) efflux transporters, p53 mutation, and deregulation of apoptotic pathways or DNA repair pathways. Despite these understandings, CRC remains one of the leading cause of cancer death worldwide, mainly due to metastasis and treatment resistance. Many studies have highlighted the relevance of exosomal miRNAs as drug-resistance mediators, revealing previously unrecognized mechanism [47-49]. Cancer cell secreted-exosomes transfer a variety of miRNAs carrying resistant clues into recipient cells and convert them to drug resistant phenotypes by targeting genes involved in the regulation of cell cycles and apoptosis. Moreover, the roles of exosomes in chemoresistance also arise from their ability to remove 
chemotherapeutic agents from cancer cells or preventing their entry into the nucleus. These novel drug resistance mechanisms have been confirmed in breast cancer, ovarian cancer, melanoma, and other types of solid tumors [50-52].

More than 10 years ago, cancer stem cell (CSC) has been described as the origin of various cancers and is associated to disease progression [53]. These CSC populations are rare, and are functionally and phenotypically different form the bulk of tumor cells. CSCs are not only resistant to the conventional chemotherapy, but also are more enriched after chemotherapy [54]. Importantly, CSCs acquire self-renewal function and are poised to propagate, leading to therapeutic failure and cancer recurrence $[55,56]$. Recent studies also proved the involvement of exosomes in CSC formation and resistance to cell death caused by chemotherapy both in vitro and in vivo [57, 58]. Fibroblasts-derived exosomes trigger spheroid formation and tumorigenic ability of CSCs through the Wnt signaling pathway, thus enhancing drug resistance [58]. The miRNA-200 family members released from exosomes were confirmed to suppress EMT-regulating transcription factors. The absence of miR-200c, miR-141 and miR-429 in 5-fluorouraclil-resistant colon cancer cells sensitized LECs (lymphendothelial cells) to the migratory signal and accelerated CCIDs formation in BEC-barrier [41, 59].

\section{Clinical potential of exosomes in CRC patients}

Given the important roles of exosomes in tumor formation, invasion and metastasis, and chemoresistance, exosomes have now been considered as an excellent source of diagnostic markers or therapeutic targets for CRC patients.

\section{Novel biomarkers}

Early studies quantifying the total amount of exosomes in plasma samples using flow cytometry have demonstrated that the fraction of exosomes in CRC patients were more than two-fold higher than in healthy controls [60]. Furthermore, elevated levels of exosomes in plasma of patients have been associated with high levels of cancer antigen and with poorly differentiated tumors. CRC patients with high amount of plasma exosomes survived shorter than those with low levels [60]. miRNAs encapsulated in exosomes are typically transported to the circulation to modulate target cells, thereby playing an important role in CRC progression. Many investigations have confirmed the abnormal expression level of particular miRNAs in body fluids of CRC patient as reliable biomarkers for early diagnosis and staging assessment. A panel of seven exosomal miRNAs, including let-7a, miR-1229, miR-1246, miR-150, miR-21, miR-223, and miR-23a, are found to be expressed significantly higher in the serum of primary CRC patients, even in those with early stage disease, than in healthy controls. Importantly, their levels decreased significantly after surgical resection of tumors [61]. In addition, the difference in expression of diverse miRNAs derived from exosomes in CRC patients' serum before and after therapy is the basis for evaluation of therapeutic effect and prognosis. For example, exosomal miR-17-92a cluster expression level in serum correlates with the recurrence of CRC. This case-control study also reported that patients after surgery with high level of serum exosomal miRNA-19a exhibited poor prognosis in contrast to those with low expression [62]. Clancy and coworkers engineered HCT116 cells to express miR-379 within exosomes. These cells exhibit significantly depressed cells proliferation and migration [63]. Recently, a novel mechanism by which exosome indirectly contribute to progression of CRC was reported [64]. Tumor-suppressive miR-193a was selectively sorted out form cancer cells into exosome in a major vault protein (MVP)-dependent manner. Hence, the level of circulating exosomal miR-193a has proved to be higher in $\mathrm{CRC}$ patients with more advanced disease compared with those with early stage of CRC and healthy controls [64].

CircRNAs (Circular RNAs), which are more abundant in exosomes than in the parental cells, participate in the process of cancer progression. CircRNAs from colorectal cancer cells with different KRAS status were analyzed. The result showed the down-regulation of circular RNAs in KRAS mutant DLD-1, DKO-1 and HCT116 cells compared with CRC cells carrying wildtype KRAS (DKs-8 and HKe3) [65]. This evidence suggests that circRNAs could be used as a class of new biomarkers for screening CRC patients with mutant KRAS gene for risk and prognostic assessment.

With the advance in mass spectrometry-based proteomic tools, coupled with improved purification methods for exosomes, the proteomic cataloguing of exosomes from diverse cancer types has revealed some common membrane and cytosolic proteins, as well as a set of proteins specific for different type of cancers, reflecting the original host cell. Chen and colleagues discovered that 36 proteins were upregulated and 22 proteins were downregulated in the serum-purified exosomes (SPEs) of CRC patients as compared to normal volunteers [66]. Pathway and network analysis revealed two interaction hubs centered on the proteins FN1 and matrix metalloproteinase-9 (MMP9), which are upregulated in the SPEs of CRC patients and pathways that are involved in cytoskeletal organization and integrin signaling in tumor progression and metastasis by reprogramming tumor microenvironment [66]. It has been consistently validated that heat shock protein 60 (Hsp60) plays a pivotal role in tumorigenesis. Hsp60 is found to be increased in exosomes liberated by tumor cells and circulated in the blood system. Interestingly, exosomal and circulating Hsp60 soon return to normal level after surgical resection of CRC tumor [67]. Therefore, exosomal Hsp60 could serve as a novel biomarker for the diagnosis of CRC and estimate of cancer treatment. 


\section{New strategies for anticancer therapy}

The remarkable success in translating basic science into survival in recent years is adoptive cell therapies with chimeric antigen receptor (CAR) engineered $\mathrm{T}$ cells (CAR-T) and immune checkpoint inhibitors in certain types of hematologic malignancies and solid tumors [68]. Dendritic cells (DCs) are potent antigen-presenting cells (APCs), originating from a common progenitor, the monocyte and dendritic cell progenitor (MDP) in bone marrow [69]. DCs play a key role in regulating both innate immune response and adaptive immune response [70].

Thus, DCs as "Nature's adjuvant" have been tested in numerous clinical trials as cellular mediators for therapeutic vaccination of patients with cancer [71]. Soon after the discovery of exosome, researchers demonstrated that exosomes secreted by DCs, also known as dendritic cell-derived exosomes (Dex), can modulate immune response against cancer [72]. Pioneer work using immuneelectron microscopy and proteomic technique revealed that Dex contain abundant MHC class I, MHC class II molecules, CD63, CD81, intergrins, milk fat globule-EGFfactor VIII [MFG-E8]), and other membrane proteins, displaying strong immunostimulatory characteristics $[73,74]$. In a preclinical mouse model, exosomes derived from tumor peptide-loaded DCs demonstrated better antitumor potency than tumor peptide-loaded DCs themselves, eliciting tumor-specific cytotoxic T lymphocytes (CTLs) response [73]. The first two clinical trials using autologous Dex loaded with the MAGE tumor antigens in patients with non-small cell lung cancer (NSCLC) or melanoma in 2005 reported that Dex therapy was safe and activation of immune effectors was observed $[75,76]$.

After these two initial trials, the feasibility and effectiveness of Dex-based immunotherapy have been explored in other types of cancers too, including CRC. It is important that exosomes trigger anti-tumor immunity [77]. Several studies have demonstrated that exosomes secreted from cells such as dendritic cells (DCs), mast cells and activated $\mathrm{T}$ and $\mathrm{B}$ cells regulate the adaptive immunity [78, 79]. Cancer cell-derived exosomes not only inhibit natural killer (NK) cell proliferation and cytotoxic effect but also induces $\mathrm{T}$ cell apoptosis by carrying Fas ligand [80, 81]. DC-derived exosomes with T-cell-dependent antitumor effect have been

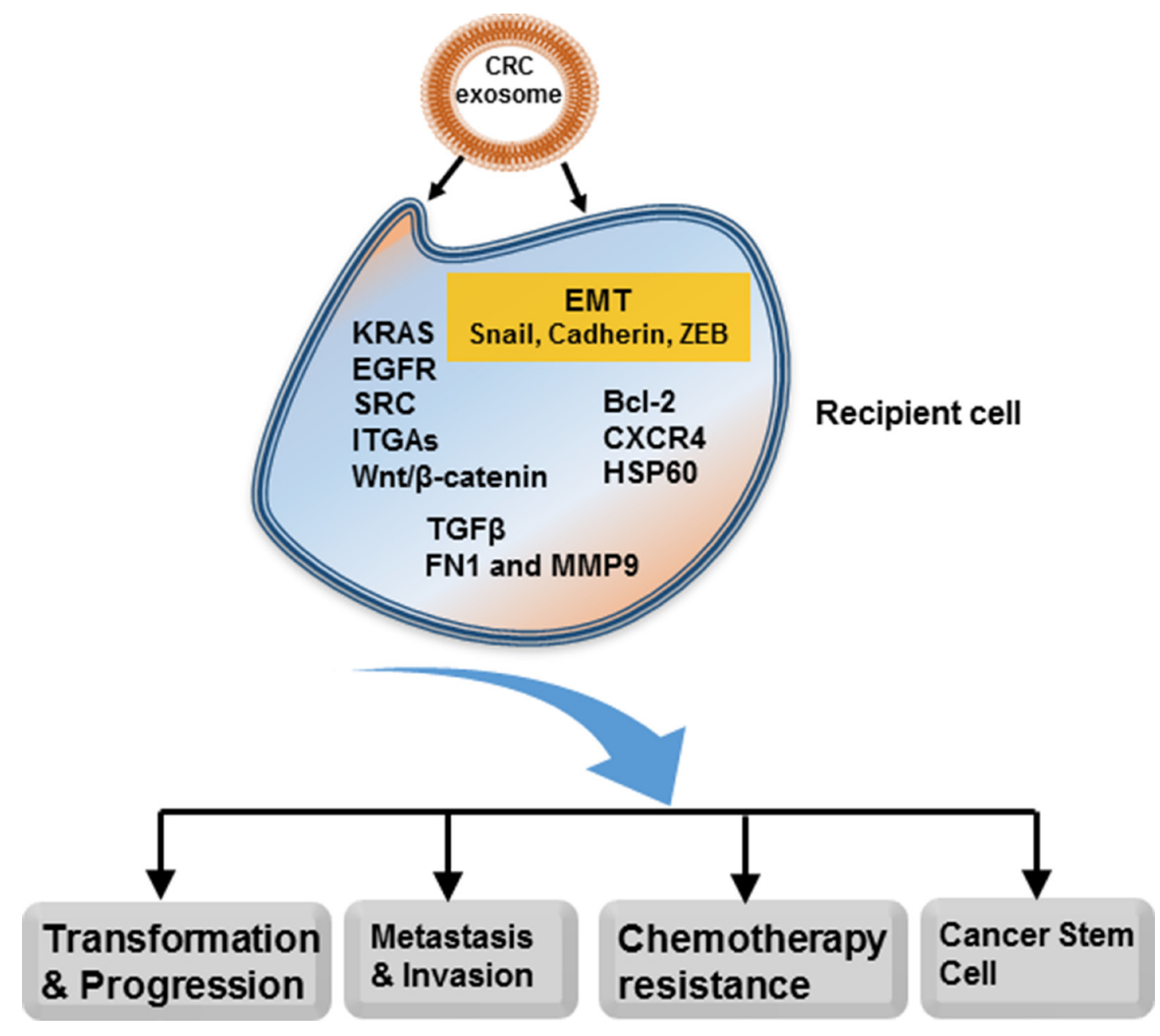

Figure 1: Multiple roles of exosomes in CRC. Exosomes can activate critical oncogenic signaling pathways in the recipient cells (cancer cells or niche cells) to promote tumor transformation, progression, invasion and metastasis. Exosomes are also involved in formation of cancer stem cells and development of drug resistance. CRC-derived exosomes can modulate biological functions of recipient cells through locally and systemically transferring proteins, DNAs, mRNAs, miRNAs, lncRNAs, lipids, etc. 
evolving to a phase II trial in France. In China, phase I clinical trial for advanced $\mathrm{CRC}$ has been performed with ascites-derived exosomes (Aex) and GM-CSF (granulocyte-macrophage colony-stimulating factor). The combination of Aex and GM-CSF efficiently induces antitumor cytotoxic $\mathrm{T}$ lymphocyte response as a safe and viable immunotherapy of advanced CRC [82]. In short, DC-mediated immunotherapy combined with GM-CSF or chemotherapy produces longer survival benefit in CRC patients, especially at the metastatic stage. Overall, Dex has proven to be safe and feasible, however, its clinical success was only limited in a few small trials. To achieve broader and sustainable clinical response, more research should focus on engineering exosome to elicit stronger anticancer immunogenicity. Given the remarkable advance in bioengineering and oncoimmunology, exosome-based immunotherapy alone or in combination with other established therapeutics could be one of the important ammunition to fight against cancer in the future.

In addition to engineering miRNA into exosomes, it should also be noted that exosomes could be used as vector in the delivery of chemotherapeutic drugs, replacing liposomes. Exosomal delivery system has the advantages of slower clearance from the bloodstream, thus increasing effectiveness of delivery, as well as higher specificity for CRC cells.

\section{Future perspectives}

Because of their small size and diverse population, the precise mechanisms of exosomes biogenesis and their multiple impacts on CRC cells and tumor microenvironment through paracrine, autocrine and telecrine routes are not well-defined and need to be further delineated. Accumulating data confirm that exosomes have a strong impact on the tumor initiation, progression, chemoresistance and metastasis of CRC (Figure 1). The application of exosomes as a novel diagnostic and therapeutic strategy have been confirmed by multiple researches in cell lines, animal models and human body fluids. However, the clinical utilities of the mentioned exosomal miRNA or proteins as biomarkers in diagnosis or prognosis of $\mathrm{CRC}$ patients require large, randomized clinical trials for further validation. Moreover, it remains unexplored whether exosomal biomarkers allow an earlier detection of CRC than other existing markers. Similarly, further translational studies and carefully designed clinical trials are essential to prove the therapeutic values of exosomes as delivery vector, exosome-based immunotherapy, or exosomes as target in CRC. These approaches could be used alone or in combination with established regimes such as chemotherapy, to treat CRC. They represent promising therapeutic opportunities especially for patients with metastatic CRC.

\section{ACKNOWLEDGMENTS}

The authors thank Ms Celestina Chin Ai Qi (CSI Singapore) for writing editing. We thank the anonymous reviewers for their critical suggestions for improving this article.

\section{CONFLICTS OF INTEREST}

The authors declare no conflicts of interesting.

\section{FINANCIAL SUPPORT}

This research is supported by the National Research Foundation Singapore and the Singapore Ministry of Education under its Research Centres of Excellence initiative (WJ Chng) and NMRC Clinician-Scientist IRG Grant CNIG11nov38 (J.Z.). W.J.C. is also supported by NMRC Clinician Scientist Investigator award. This study is also partially supported by the RNA Biology Center at CSI Singapore, NUS, from funding by the Singapore Ministry of Education's Tier 3 grants, grant number MOE2014-T3-1-006.

\section{REFERENCES}

1. Chiba M, Kimura M, Asari S. Exosomes secreted from human colorectal cancer cell lines contain mRNAs, microRNAs and natural antisense RNAs, that can transfer into the human hepatoma HepG2 and lung cancer A549 cell lines. Oncol Rep. 2012; 28:1551-1558.

2. Kalra H, Drummen GP, Mathivanan S. Focus on Extracellular Vesicles: Introducing the Next Small Big Thing. Int J Mol Sci. 2016; 17:170.

3. Azmi AS, Bao B, Sarkar FH. Exosomes in cancer development, metastasis, and drug resistance: a comprehensive review. Cancer Metastasis Rev. 2013; 32:623-642.

4. Brenner H, Kloor M, Pox CP. Colorectal cancer. Lancet. 2014; 383:1490-1502.

5. Pan BT, Teng K, Wu C, Adam M, Johnstone RM. Electron microscopic evidence for externalization of the transferrin receptor in vesicular form in sheep reticulocytes. J Biol Chem. 1985; 101:942-948.

6. Johnstone RM, Adam M, Hammond JR, Orr L, Turbide C. Vesicle formation during reticulocyte maturation. Association of plasma membrane activities with released vesicles (exosomes). J Biol Chem. 1987; 262:9412-9420.

7. Zhou J, Wang S, Sun K, Chng WJ. The emerging roles of exosomes in leukemogeneis. Oncotarget. 2016; 7: 50698-50707. https://doi.org/10.18632/oncotarget.9333.

8. Shao Y, Shen Y, Chen T, Xu F, Chen X, Zheng S. The functions and clinical applications of tumor-derived exosomes. Oncotarget. 2016; 7:60736-60751. https://doi. org/10.18632/oncotarget.11177. 
9. Caby MP, Lankar D, Vincendeau-Scherrer C, Raposo G, Bonnerot C. Exosomal-like vesicles are present in human blood plasma. Int Immunol. 2005; 17:879-887.

10. Pisitkun T, Shen RF, Knepper MA. Identification and proteomic profiling of exosomes in human urine. Proc Natl Acad Sci USA. 2004; 101:13368-13373.

11. Ogawa Y, Kanai-Azuma M, Akimoto Y, Kawakami H, Yanoshita R. Exosome-like vesicles with dipeptidyl peptidase IV in human saliva. Biol Pharm Bull. 2008; 31:1059-1062.

12. Hosseini M, Khatamianfar S, Hassanian SM, Nedaeinia R, Shafiee M, Maftouh M, Ghayour-Mobarhan M, Sales SS, Avan A. Exosome-encapsulated microRNAs as potential circulating biomarkers in colon cancer. Curr Pharm Des. 2017; 23:1705-1709.

13. Kalluri R. The biology and function of exosomes in cancer. J Clin Invest. 2016; 126:1208-1215.

14. Babst M. MVB vesicle formation: ESCRT-dependent, ESCRT-independent and everything in between. Curr Opin Cell Biol. 2011; 23:452-457.

15. Trajkovic K, Hsu C, Chiantia S, Rajendran L, Wenzel D, Wieland F, Schwille P, Brugger B, Simons M. Ceramide triggers budding of exosome vesicles into multivesicular endosomes. Science. 2008; 319:1244-1247.

16. Ostrowski M, Carmo NB, Krumeich S, Fanget I, Raposo G, Savina A, Moita CF, Schauer K, Hume AN, Freitas RP, Goud B, Benaroch P, Hacohen N, et al. Rab27a and Rab27b control different steps of the exosome secretion pathway. Nat Cell Biol. 2010; 12:19-30; 11-13.

17. Thery C, Ostrowski M, Segura E. Membrane vesicles as conveyors of immune responses. Nat Rev Immunol. 2009; 9:581-593.

18. Hergenreider E, Heydt S, Treguer K, Boettger $T$, Horrevoets AJ, Zeiher AM, Scheffer MP, Frangakis AS, Yin X, Mayr M, Braun T, Urbich C, Boon RA, et al. Atheroprotective communication between endothelial cells and smooth muscle cells through miRNAs. Nat Cell Biol. 2012; 14:249-256.

19. Kowal J, Arras G, Colombo M, Jouve M, Morath JP, Primdal-Bengtson B, Dingli F, Loew D, Tkach M, Thery C. Proteomic comparison defines novel markers to characterize heterogeneous populations of extracellular vesicle subtypes. Proc Natl Acad Sci USA. 2016; 113:E968-977.

20. Melo SA, Sugimoto H, O'Connell JT, Kato N, Villanueva A, Vidal A, Qiu L, Vitkin E, Perelman LT, Melo CA, Lucci A, Ivan C, Calin GA, et al. Cancer exosomes perform cell-independent microRNA biogenesis and promote tumorigenesis. Cancer cell. 2014; 26:707-721.

21. Skog J, Wurdinger T, van Rijn S, Meijer DH, Gainche L, Sena-Esteves M, Curry WT Jr, Carter BS, Krichevsky AM, Breakefield XO. Glioblastoma microvesicles transport RNA and proteins that promote tumour growth and provide diagnostic biomarkers. Nat Cell Biol. 2008; 10:1470-1476.

22. Camp ER, Ellis LM. CCR 20th Anniversary Commentary: RAS as a Biomarker for EGFR--Targeted Therapy for
Colorectal Cancer-From Concept to Practice. Clin Cancer Res. 2015; 21:3578-3580.

23. Cha DJ, Franklin JL, Dou Y, Liu Q, Higginbotham JN, Demory Beckler M, Weaver AM, Vickers K, Prasad N, Levy S, Zhang B, Coffey RJ, Patton JG. KRAS-dependent sorting of miRNA to exosomes. Elife. 2015; 4:e07197.

24. Demory Beckler M, Higginbotham JN, Franklin JL, Ham AJ, Halvey PJ, Imasuen IE, Whitwell C, Li M, Liebler DC, Coffey RJ. Proteomic analysis of exosomes from mutant KRAS colon cancer cells identifies intercellular transfer of mutant KRAS. Mol Cell Proteomics. 2013; 12:343-355.

25. Valcz G, Galamb O, Krenacs T, Spisak S, Kalmar A, Patai AV, Wichmann B, Dede K, Tulassay Z, Molnar B. Exosomes in colorectal carcinoma formation: ALIX under the magnifying glass. Mod Pathol. 2016; 29:928-938.

26. Webber JP, Spary LK, Sanders AJ, Chowdhury R, Jiang WG, Steadman R, Wymant J, Jones AT, Kynaston H, Mason MD, Tabi Z, Clayton A. Differentiation of tumourpromoting stromal myofibroblasts by cancer exosomes. Oncogene. 2015; 34:290-302.

27. Huang Z, Feng Y. Exosomes derived from hypoxic colorectal cancer cells promotes angiogenesis through Wnt4 induced beta-catenin signaling in endothelial cells. Oncol Res. 2016.

28. Takayama T, Miyanishi K, Hayashi T, Sato Y, Niitsu Y. Colorectal cancer: genetics of development and metastasis. J Gastroenterol. 2006; 41:185-192.

29. Markowitz SD, Bertagnolli MM. Molecular origins of cancer: Molecular basis of colorectal cancer. N Engl J Med. 2009; 361:2449-2460.

30. Fearon ER. Molecular genetics of colorectal cancer. Annu Rev Pathol. 2011; 6:479-507.

31. Qiu M, Hu J, Yang D, Cosgrove DP, Xu R. Pattern of distant metastases in colorectal cancer: a SEER based study. Oncotarget. 2015; 6:38658-38666. https://doi. org/10.18632/oncotarget.6130.

32. Obenauf AC, Massague J. Surviving at a distance: organ specific metastasis. Trends Cancer. 2015; 1:76-91.

33. Budczies J, von Winterfeld M, Klauschen F, Bockmayr M, Lennerz JK, Denkert C, Wolf T, Warth A, Dietel M, Anagnostopoulos I, Weichert W, Wittschieber D, Stenzinger A. The landscape of metastatic progression patterns across major human cancers. Oncotarget. 2015; 6:570-583. https://doi.org/10.18632/oncotarget.2677.

34. Hoshino A, Costa-Silva B, Shen TL, Rodrigues G, Hashimoto A, Tesic Mark M, Molina H, Kohsaka S, Di Giannatale A, Ceder S, Singh S, Williams C, Soplop N, et al. Tumour exosome integrins determine organotropic metastasis. Nature. 2015; 527:329-335.

35. Costa-Silva B, Aiello NM, Ocean AJ, Singh S, Zhang H, Thakur BK, Becker A, Hoshino A, Mark MT, Molina H, Xiang J, Zhang T, Theilen TM, et al. Pancreatic cancer exosomes initiate pre-metastatic niche formation in the liver. Nat Cell Biol. 2015; 17:816-826. 
36. Zomer A, Maynard C, Verweij FJ, Kamermans A, Schafer R, Beerling E, Schiffelers RM, de Wit E, Berenguer J, Ellenbroek SI, Wurdinger T, Pegtel DM, van Rheenen J. In Vivo imaging reveals extracellular vesicle-mediated phenocopying of metastatic behavior. Cell. 2015; 161: 1046-1057.

37. Lugini L, Valtieri M, Federici C, Cecchetti S, Meschini S, Condello M, Signore M, Fais S. Exosomes from human colorectal cancer induce a tumor-like behavior in colonic mesenchymal stromal cells. Oncotarget. 2016; 7:5008650098. https://doi.org/10.18632/oncotarget.10574.

38. Bigagli E, Luceri C, Guasti D, Cinci L. Exosomes secreted from human colon cancer cells influence the adhesion of neighboring metastatic cells: Role of microRNA-210. Cancer Biol Ther. 2016:1-8.

39. Nieto MA, Huang RY, Jackson RA, Thiery JP. Emt: 2016. Cell. 2016; 166:21-45.

40. Gopal SK, Greening DW, Rai A, Chen M, Xu R, Shafiq A, Mathias RA, Zhu HJ, Simpson RJ. Extracellular vesicles: their role in cancer biology and epithelial-mesenchymal transition. Biochem J. 2017; 474:21-45.

41. Holzner S, Senfter D, Stadler S, Staribacher A, Nguyen CH, Gaggl A, Geleff S, Huttary N, Krieger S, Jager W, Dolznig H, Mader RM, Krupitza G. Colorectal cancer cell-derived microRNA200 modulates the resistance of adjacent blood endothelial barriers in vitro. Oncol Rep. 2016; 36:3065-3071.

42. Zaharie F, Muresan MS, Petrushev B, Berce C, Gafencu GA, Selicean S, Jurj A, Cojocneanu-Petric R, Lisencu CI, Pop LA, Pileczki V, Eniu D, Muresan MA, et al. ExosomeCarried microRNA-375 Inhibits Cell Progression and Dissemination via Bcl-2 Blocking in Colon Cancer. J Gastrointestin Liver Dis. 2015; 24:435-443.

43. Wang X, Ding X, Nan L, Wang Y, Wang J, Yan Z, Zhang W, Sun J, Zhu W, Ni B, Dong S, Yu L. Investigation of the roles of exosomes in colorectal cancer liver metastasis. Oncol Rep. 2015; 33:2445-2453.

44. Ji H, Greening DW, Barnes TW, Lim JW, Tauro BJ, Rai A, Xu R, Adda C, Mathivanan S, Zhao W, Xue Y, Xu T, Zhu $\mathrm{HJ}$, et al. Proteome profiling of exosomes derived from human primary and metastatic colorectal cancer cells reveal differential expression of key metastatic factors and signal transduction components. Proteomics. 2013; 13:1672-1686.

45. Li XL, Zhou J, Chan ZL, Chooi JY, Chen ZR, Chng WJ. PRIMA-1met (APR-246) inhibits growth of colorectal cancer cells with different p53 status through distinct mechanisms. Oncotarget. 2015; 6:36689-36699. https:// doi.org/10.18632/oncotarget.5385.

46. Li XL, Zhou J, Chen ZR, Chng WJ. P53 mutations in colorectal cancer - molecular pathogenesis and pharmacological reactivation. World J Gastroenterol. 2015; 21:84-93.

47. Nakamura K, Sawada K, Kinose Y, Yoshimura A, Toda A, Nakatsuka E, Hashimoto K, Mabuchi S, Morishige KI, Kurachi H, Lengyel E, Kimura T. Exosomes Promote Ovarian Cancer Cell Invasion through Transfer of CD44 to Peritoneal Mesothelial Cells. Mol Cancer Res. 2017; 15:78-92.
48. Yu S, Cao H, Shen B, Feng J. Tumor-derived exosomes in cancer progression and treatment failure. Oncotarget. 2015; 6:37151-37168. https://doi.org/10.18632/oncotarget.6022.

49. Zhou J, Chan ZL, Bi C, Lu X, Chong PS, Chooi JY, Cheong LL, Liu SC, Ching YQ, Zhou Y, Osato M, Tan TZ, $\mathrm{Ng} \mathrm{CH}$, et al. LIN28B Activation by PRL-3 Promotes Leukemogenesis and a Stem Cell-like Transcriptional Program in AML. Mol Cancer Res. 2017; 15:294-303.

50. Santos JC, Ribeiro ML, Sarian LO, Ortega MM, Derchain SF. Exosomes-mediate microRNAs transfer in breast cancer chemoresistance regulation. Am J Cancer Res. 2016; 6:2129-2139.

51. Yin J, Yan X, Yao X, Zhang Y, Shan Y, Mao N, Yang Y, Pan L. Secretion of annexin A3 from ovarian cancer cells and its association with platinum resistance in ovarian cancer patients. J Cell Mol Med. 2012; 16:337-348.

52. Federici C, Petrucci F, Caimi S, Cesolini A, Logozzi M, Borghi M, D'Ilio S, Lugini L, Violante N, Azzarito T, Majorani C, Brambilla D, Fais S. Exosome release and low $\mathrm{pH}$ belong to a framework of resistance of human melanoma cells to cisplatin. PLoS One. 2014; 9:e88193.

53. Zhou J, Chng WJ. Aberrant RNA splicing and mutations in spliceosome complex in acute myeloid leukemia. Stem Cell Investig. 2017; 4:6.

54. Todaro M, Francipane MG, Medema JP, Stassi G. Colon cancer stem cells: promise of targeted therapy. Gastroenterology. 2010; 138:2151-2162.

55. Zhou J, Chng WJ. Identification and targeting leukemia stem cells: The path to the cure for acute myeloid leukemia. World J Stem Cells. 2014; 6:473-484.

56. Tauriello DV, Calon A, Lonardo E, Batlle E. Determinants of metastatic competency in colorectal cancer. Mol Oncol. 2017; 11:97-119.

57. Dallas NA, Xia L, Fan F, Gray MJ, Gaur P, van Buren G 2nd, Samuel S, Kim MP, Lim SJ, Ellis LM. Chemoresistant colorectal cancer cells, the cancer stem cell phenotype, and increased sensitivity to insulin-like growth factor-I receptor inhibition. Cancer Res. 2009; 69:1951-1957.

58. Hu Y, Yan C, Mu L, Huang K, Li X, Tao D, Wu Y, Qin J. Fibroblast-Derived Exosomes Contribute to Chemoresistance through Priming Cancer Stem Cells in Colorectal Cancer. PLoS One. 2015; 10:e125625.

59. Senfter D, Holzner S, Kalipciyan M, Staribacher A, Walzl A, Huttary N, Krieger S, Brenner S, Jager W, Krupitza G, Dolznig H, Mader RM. Loss of miR-200 family in 5-fluorouracil resistant colon cancer drives lymphendothelial invasiveness in vitro. Hum Mol Genet. 2015; 24:3689-3698.

60. Silva J, Garcia V, Rodriguez M, Compte M, Cisneros E, Veguillas P, Garcia JM, Dominguez G, Campos-Martin Y, Cuevas J, Pena C, Herrera M, Diaz R, et al. Analysis of exosome release and its prognostic value in human colorectal cancer. Genes Chromosomes Cancer. 2012; 51:409-418. 
61. Ogata-Kawata H, Izumiya M, Kurioka D, Honma Y, Yamada Y, Furuta K, Gunji T, Ohta H, Okamoto H, Sonoda $\mathrm{H}$, Watanabe M, Nakagama H, Yokota J, et al. Circulating exosomal microRNAs as biomarkers of colon cancer. PLoS One. 2014; 9:e92921.

62. Matsumura $\mathrm{T}$, Sugimachi $\mathrm{K}$, Iinuma H, Takahashi $\mathrm{Y}$, Kurashige J, Sawada G, Ueda M, Uchi R, Ueo H, Takano Y, Shinden Y, Eguchi H, Yamamoto H, et al. Exosomal microRNA in serum is a novel biomarker of recurrence in human colorectal cancer. Br J Cancer. 2015; 113:275-281.

63. Clancy C, Khan S, Glynn CL, Holian E, Dockery P, Lalor P, Brown JA, Joyce MR, Kerin MJ, Dwyer RM. Screening of exosomal microRNAs from colorectal cancer cells. Cancer Biomark. 2016; 17:427-435.

64. Teng Y, Ren Y, Hu X, Mu J, Samykutty A, Zhuang X, Deng Z, Kumar A, Zhang L, Merchant ML, Yan J, Miller DM, Zhang HG. MVP-mediated exosomal sorting of miR193a promotes colon cancer progression. Nat Commun. 2017; 8:14448.

65. Dou Y, Cha DJ, Franklin JL, Higginbotham JN, Jeppesen DK, Weaver AM, Prasad N, Levy S, Coffey RJ, Patton JG, Zhang B. Circular RNAs are down-regulated in KRAS mutant colon cancer cells and can be transferred to exosomes. Sci Rep. 2016; 6:37982.

66. Chen Y, Xie Y, Xu L, Zhan S, Xiao Y, Gao Y, Wu B, Ge W. Protein content and functional characteristics of serumpurified exosomes from patients with colorectal cancer revealed by quantitative proteomics. Int J Cancer. 2017; 140:900-913.

67. Campanella C, Rappa F, Sciume C, Marino Gammazza A, Barone R, Bucchieri F, David S, Curcuru G, Caruso Bavisotto C, Pitruzzella A, Geraci G, Modica G, Farina F, et al. Heat shock protein 60 levels in tissue and circulating exosomes in human large bowel cancer before and after ablative surgery. Cancer. 2015; 121:3230-3239.

68. Stambrook PJ, Maher J, Farzaneh F. Cancer Immunotherapy: Whence and Whither. Mol Cancer Res. 2017; 15:635-650.

69. Liu K, Nussenzweig MC. Origin and development of dendritic cells. Immunol Rev. 2010; 234:45-54.

70. O’Neill DW, Adams S, Bhardwaj N. Manipulating dendritic cell biology for the active immunotherapy of cancer. Blood. 2004; 104:2235-2246.

71. Bol KF, Schreibelt G, Gerritsen WR, de Vries IJ, Figdor CG. Dendritic Cell-Based Immunotherapy: State of the Art and Beyond. Clin Cancer Res. 2016; 22:1897-1906.

72. Zhang B, Yin Y, Lai RC, Lim SK. Immunotherapeutic potential of extracellular vesicles. Front Immunol. 2014; 5:518.

73. Zitvogel L, Regnault A, Lozier A, Wolfers J, Flament C, Tenza D, Ricciardi-Castagnoli P, Raposo G, Amigorena S.
Eradication of established murine tumors using a novel cellfree vaccine: dendritic cell-derived exosomes. Nat Med. 1998; 4:594-600.

74. Thery C, Regnault A, Garin J, Wolfers J, Zitvogel L, Ricciardi-Castagnoli P, Raposo G, Amigorena S. Molecular characterization of dendritic cell-derived exosomes. Selective accumulation of the heat shock protein hsc73. J Cell Biol. 1999; 147:599-610.

75. Morse MA, Garst J, Osada T, Khan S, Hobeika A, Clay TM, Valente N, Shreeniwas R, Sutton MA, Delcayre A, Hsu DH, Le Pecq JB, Lyerly HK. A phase I study of dexosome immunotherapy in patients with advanced non-small cell lung cancer. J Transl Med. 2005; 3:9.

76. Escudier B, Dorval T, Chaput N, Andre F, Caby MP, Novault S, Flament C, Leboulaire C, Borg C, Amigorena S, Boccaccio C, Bonnerot C, Dhellin O, et al. Vaccination of metastatic melanoma patients with autologous dendritic cell (DC) derived-exosomes: results of thefirst phase I clinical trial. J Transl Med. 2005; 3:10.

77. Viaud S, Ploix S, Lapierre V, Thery C, Commere PH, Tramalloni D, Gorrichon K, Virault-Rocroy P, Tursz T, Lantz O, Zitvogel L, Chaput N. Updated technology to produce highly immunogenic dendritic cell-derived exosomes of clinical grade: a critical role of interferongamma. J Immunother. 2011; 34:65-75.

78. Hwang I, Shen X, Sprent J. Direct stimulation of naive T cells by membrane vesicles from antigen-presenting cells: distinct roles for CD54 and B7 molecules. Proc Natl Acad Sci USA. 2003; 100:6670-6675.

79. Skokos D, Botros HG, Demeure C, Morin J, Peronet R, Birkenmeier G, Boudaly S, Mecheri S. Mast cell-derived exosomes induce phenotypic and functional maturation of dendritic cells and elicit specific immune responses in vivo. J Immunol. 2003; 170:3037-3045.

80. Clayton A, Mitchell JP, Court J, Linnane S, Mason MD, Tabi Z. Human tumor-derived exosomes down-modulate NKG2D expression. J Immunol. 2008; 180:7249-7258.

81. Andreola G, Rivoltini L, Castelli C, Huber V, Perego P, Deho P, Squarcina P, Accornero P, Lozupone F, Lugini L, Stringaro A, Molinari A, Arancia G, et al. Induction of lymphocyte apoptosis by tumor cell secretion of FasLbearing microvesicles. J Exp Med. 2002; 195:1303-1316.

82. Dai S, Wei D, Wu Z, Zhou X, Wei X, Huang H, Li G. Phase I clinical trial of autologous ascites-derived exosomes combined with GM-CSF for colorectal cancer. Mol Ther. 2008; 16:782-790.

83. Tanaka S, Hosokawa M, Ueda K, Iwakawa S. Effects of Decitabine on Invasion and Exosomal Expression of miR200c and miR-141 in Oxaliplatin-Resistant Colorectal Cancer Cells. Biol Pharm Bull. 2015; 38:1272-1279. 